\title{
Keeping Our Eyes on the Prize: Focusing on Parenting Supports Depressed Parents' Involvement in Home Visiting Services
}

\author{
Lorraine M. McKelvey $^{1}$ (i) $\cdot$ Shalese Fitzgerald ${ }^{1} \cdot$ Nicola A. Conners Edge $^{1} \cdot$ Leanne Whiteside-Mansell $^{1}$
}

Published online: 28 May 2018

(C) The Author(s) 2018, Corrected publication August/2018

\begin{abstract}
Objectives Improving family retention and engagement is crucial to the success of home visiting programs. Little is known about retaining and engaging depressed parents in services. The purpose of the study is to examine how home visit content moderates the association between depression and retention and engagement. Methods The sample $(\mathrm{N}=1322)$ was served by Healthy Families America $(n=618)$ and Parents as Teachers $(n=704)$ between April 1, 2012 and June 30, 2016. Parents averaged 23 years $(\mathrm{SD}=6)$. Nearly half of the parents were White $(48 \%)$ and the majority was single $(71 \%)$. Depression was screened with the Patient Health Questionnaire-2. Home visitors reported the percent of time focused on particular content and parent engagement at every home visit. Results Multilevel regression analyses showed the amount of time that home visitors spent supporting parent-child interaction moderated the association between depression and retention at 6 $(B=.08, S E=.03, p=.003)$ and $12(B=.1, S E=.03, p<.001)$ months, such that there was a stronger positive association for depressed parents. The main effects of child development focused content and retention at $6(B=.07, S E=.01, p<.001)$ and $12(B=.08, S E=.01, p<.001)$ months were positive, while effects of case management focused content at $6(B=-.06$, $S E=.01, p<.001)$ and $12(B=-.07, S E=.01, p<.001)$ months were negative. Conclusions Families were more likely to be retained when home visitors focused on child development and parent-child interaction, but less likely with more case management focus. Parents with positive depression screens were more likely to remain in services with more time spent focused on supporting parent-child interactions.
\end{abstract}

Keywords Home visiting $\cdot$ Depression $\cdot$ Retention $\cdot$ Family engagement

\section{Significance}

Depressive symptoms are common among parents receiving home visiting services and may impede the effectiveness of the intervention. Our findings provide guidance to home visitors, indicating that they may increase the likelihood that parents will remain in the intervention if they stay focused on supporting the parent-child relationship. This is especially true for parents with depressive symptoms.

Lorraine M. McKelvey

mckelveylorraine@uams.edu

1 Department of Family and Preventive Medicine, College of Medicine, University of Arkansas for Medical Sciences, 4301 W. Markham St, \#530, Little Rock, AR 72205-7199, USA

\section{Introduction}

Parental depression has significant negative impacts on children's development. A meta-analysis of 46 studies (Lovejoy et al. 2000) reported that depression interferes with the parent's capacity to provide engaged and positive caregiving. Specifically, maternal depression significantly increased the likelihood of interactions where maternal behaviors with children were negative in affect (i.e., irritable, hostile or coercive) and were less emotionally available, reciprocal, and positive in interactions with their children. Findings from the study are especially salient during infancy. Further, the effects of depression in infancy are evident even when depressive symptoms do not meet the criteria for a major depressive disorder (Conners-Burrow et al. 2014, 2015, 2016).

Home visiting interventions provide one avenue to improve child outcomes in families where children are at risk, including when parents are depressed. The theory of 
change for many evidence-based home visiting (EBHV) interventions is to promote the optimal growth and development of children through enhancing the quality of parenting and family environments (Raikes et al. 2014). While most EBHV programs do not purposefully recruit parents with depression [notable exceptions include In-Home Cognitive Behavior Therapy through Moving Beyond Depression ${ }^{\mathrm{TM}}$; Ammerman et al. 2015 and Enhanced Triple P, (Sanders et al. 2000)], serving parents with depression is common. Results from the national study of home visiting (Mother and Infant Home Visiting Program Evaluation) suggest that $40 \%$ of mothers exhibited depression or anxiety at enrollment (MDRC 2017). Indeed, screening for depression is required when programs receive Maternal, Infant, and Early Childhood Home Visiting (MIECHV) funding. It is clear that caregivers with depression enroll in EBHV; however, what is known about their participation and persistence in programs is variable (Azzi-Lessing 2013; Sweet and Appelbaum 2004). Several studies reported no association between caregiver depression and retention in services, including: SafeCare+ (Damashek et al. 2011), Durham Connects (Navaie-Waliser et al. 2000), Nurse-Family Partnership (Brand and Jungmann 2014; O'Brien et al. 2012), and Parenting for Life (Booth et al. 2014). Similarly, a study of a French perinatal home visiting program also reported no association between program attrition and caregiver depression at enrollment but found that caregivers with higher levels of general psychiatric symptoms were less likely to remain in services (Foulon et al. 2015). Positive associations between depressive symptoms and retention in home-visitation programs have also been reported in Family Connections (Girvin et al. 2007), and Healthy Families America and NurseFamily Partnership (Ammerman et al. 2006, 2009).

Recent studies have explored associations between how the home visitor focuses the visit and engagement and retention. Home visitors may focus on facilitating parent-child interactions, (i.e., supporting reciprocity of interactions by helping the parent understand their child's cues and respond with warmth and empathy). They may also deliver childfocused content, for example, sharing information about the child's development. Other times home visitors feel obligated to address family needs and may engage in more case management like activities. In Early Head Start (EHS), the more time home visitors spent facilitating parent-child interactions (Peterson et al. 2007) and delivering child-focused content (Roggman et al. 2008), the greater parental engagement in services.

Participant engagement and attrition is a major influence on the effectiveness of home visiting programs (Azzi-Lessing 2011). It is clear that monitoring participant engagement and attrition, assessing family and program characteristics associated with attrition and engagement, and developing strategies to retain and engage at-risk families are crucial for the successful replication of EBHV programs (AzziLessing 2011, 2013). The purpose of the current study is to investigate how program process variables-specifically the percent of time home visitors focus the content of home visits on parent-child interactions, child development, and parent/family case management-influence the association between caregiver depression at enrollment and engagement and retention in services. While we are the first study to investigate whether particular program content moderates the association between program engagement and depression at enrollment, we can extrapolate from existing studies of program content provided within the Early Head Start (EHS) model. EHS serves a similar population of families as the EBHV models included in this study. Those studies, which included smaller samples of families, suggest that remaining focused on child development and parent-child interaction should increase parental engagement in programs, regardless of depressive symptoms at enrollment.

\section{Methods}

\section{Study Design}

This study uses data collected during the implementation of EBHV programs funded through the MIECHV program in Arkansas. Families included in the analysis voluntarily enrolled in two EBHV models, Healthy Families America (HFA) and Parents as Teachers (PAT), which serve expectant families and those with children up to age three. The overall goal of the HFA program is to promote child well-being and prevent abuse and neglect. The PAT program, designed as a universal parenting intervention, focuses on the promotion of optimal early development, learning, and health. Families were eligible for services if they reported characteristics associated with less optimal parenting, including (1) demographic (low-income or a single and/or teen parent), parent (such as parental history of abuse, incarceration, military deployment, disability, or chronic illness), and child (developmental delay, pre-term/low birth weight, disability, or chronic illness) risks. All families provided consent to have their data used for evaluation purposes. The University of Arkansas for Medical Sciences Institutional Review Board approved the study.

\section{Participants}

We used program process data collected about families who were enrolled for at least one month between April 1, 2012 and June 30, $2016(\mathrm{~N}=1322$; HFA $\mathrm{N}=618$, PAT $\mathrm{N}=704)$ to examine the retention and engagement patterns of parents who screened positive for depression. The majority of families (89\%) were living at or below $100 \%$ of the federal poverty 
line. Primary caregivers were 23 years old on average $(S D=6)$. Nearly half were Caucasian (48\%) with another $25 \%$ being African-American and 23\% of Hispanic ethnicity. The majority of primary caregivers reported having education at or less than a high school or general equivalency diploma (78\%) and were single (75\%). Children were 4 months of age on average $(S D=10)$ and were equally divided on gender ( $50 \%$ male). Table 1 shows family and child demographics at enrollment.

\section{Measures}

The Family Map Inventories (FMI; Whiteside-Mansell et al. 2007, 2013) were completed within 1 month of enrollment. The FMI are a set of semi-structured interviews developed to assess important aspects of the family and home environment associated with child well-being. There are three

Table 1 Sample demographics at enrollment

\begin{tabular}{ll}
\hline & $\begin{array}{l}\text { Percentage } \\
(n=1322)\end{array}$ \\
\hline Age of applicant in years $(M, S D)$ & $23(6)$ \\
Teenage motherhood & \\
Mother $<20$ & $38.5 \%$ \\
Mother 20 or older & $61.5 \%$ \\
Applicant race/ethnicity & \\
Caucasian & $48.1 \%$ \\
African-American & $25.1 \%$ \\
Hispanic & $22.7 \%$ \\
Other & $4.1 \%$ \\
Applicant education & \\
Less than high school graduate & $43.0 \%$ \\
High school graduate or equivalent & $35.4 \%$ \\
Some college or degree & $21.6 \%$ \\
Applicant employment status & \\
Unemployed & $70.6 \%$ \\
Part time & $14.0 \%$ \\
Full time & $15.4 \%$ \\
Marital status & \\
Single & \\
Married/cohabiting & \\
Separated, divorced or widowed & \\
Family income $(M, S D)$ & \\
Poverty (100\% or less) & \\
Number of adults in family $(M, S D)$ & $25.2 \%$ \\
Number of children in family $(M, S D)$ & $3.9 \%$ \\
Prenatal enrollment & $\$ 9741(\$ 8108)$ \\
Child age at enrollment in months $(M, S D)$ & $1.6(1.2)$ \\
Child is male & $1.6(1.3)$ \\
Parental depression risk (scores) at enrollment & $46.0 \%$ \\
Not at risk (0-1) & $4(10)$ \\
At risk (2 or higher) & $50.4 \%$ \\
\hline
\end{tabular}

versions of the FMI based on the age of the child at the time of assessment: Prenatal, Infant/Toddler, and Early Childhood. The instruments, designed for use during home visits, systematically identify areas of strength and concern associated with healthy child development. All versions of the FMI include the Patient Health Questionnaire-2 (Kroenke et al. 2003) screening for depression. The two-item PHQ-2 is efficient, well validated and recommended by the U.S. Preventive Services Task Force as a good screening option for depressive symptoms (Pignone et al. 2002). Response options on the PHQ-2 include 'not at all' (0), 'several days' (1), 'more than half the days' (2), and 'nearly every day' (3). Sum scores on the PHQ-2 range from 0 to 6, with higher scores representing a greater endorsement of depressive symptoms.

There are multiple recommendations for determining the cutoff of the instrument for predicting depression. In the original development study, a cutoff score of 3 was reported to have a sensitivity of $83 \%$ and a specificity of $92 \%$ for predicting major depressive disorders, while a cutoff of 2 increased the sensitivity to $93 \%$ (Kroenke et al. 2003). A recent study of a primary care population (Arroll et al. 2010) demonstrated sensitivity and specificity of the PHQ-2 for diagnosing major depression of 86 and $78 \%$ with a score of 2 or higher, and 61 and $92 \%$ with a score 3 or higher. As sensitivity of the tool increased $25 \%$ using a lower threshold and there were 63 patients with major depressive disorder that were undetected using the higher threshold, the authors concluded that individuals scoring 2 or higher should be further screened in clinical settings. There are also multiple studies that document the impact of lower-level depression on parenting in low-income samples (Conners-Burrow et al. 2014, 2015, 2016). As a result, we examine parents scoring at 2 or higher.

Home visitors documented each home visit. Program staff entered individual services into a web-based data management system, Efforts to Outcomes (ETO; Social Solutions 2016), designed to track all elements of home visiting programs, including family contacts with and without educational content, unsuccessful visits (e.g., the home visitor arrives to find no one is home), and dismissals. Home visits were documented in ETO using a Home Visit Record (HVR). The HVR was developed by modifying the Home Visit Contents and Characteristics observation record of the Baby FACES study (Vogel et al. 2011). In brief, the HVR includes the home visitor $(\mathrm{N}=96)$ reports of the percentage of the time of the total home visit that was focused on specific content (parent-childfocused, child-focused, and parent/family-focused), and home visitor ratings of parent engagement. Home visitors reported the percent of time focused on particular content and parent engagement at every home visit. The evaluation team trained home visitors on all measures. Further, 
to assure that home visitors were clear of the intent of the reporting, the evaluation team built the data system such that the HVR included the definitions described below.

We aggregated and averaged the percentages across home visits. Parent-child interaction content was defined for staff as "focused on the parent-child dyad, for example, activities to enhance parent-child interactions or the parent-child relationship" $(M=16.99, S D=12.17)$. Child development content "focused on the child and his/ her development, for example, activities with the child to promote child development, child development assessment and provision of parenting education on developmental milestones, etc." $(M=26.85, S D=19.24)$. Parent/ family content was defined as "case management, family support, and adult education on other topics" $(M=30.41$, $S D=16.87)$.

Program process outcomes examined in the current study include retention and engagement in services. There are multiple reasons why families leave services. The models included in this analysis have differing policies for discharging families. Parents as Teachers does not have a national policy and allows programs to make decisions on a caseby-case basis. Healthy Families America has a service level called "Creative Outreach" where families with whom home visitors have lost contact can remain on the caseload for 90 days as the program works to re-establish communication, but it is not required that the program use the full amount of time before replacing the client. Therefore, there is a great deal of variability in when families are discharged from services, across models, programs, and families. For all process outcomes in this study, families' dismissal dates were set to the date of their last successfully completed home visit. Family retention represents a dichotomy $(0=$ No, $1=$ Yes $)$ of remaining in the program a minimum of $6(71 \%$ retention rate) and 12 (48\% retention rate) months.

We use two measures of family engagement. We computed a home visit completion ratio, computed as the total number of completed home visits to all attempted and completed visits. Higher scores on home visit completion represent a family being accessible for home visits at a higher rate $(M=0.80, S D=0.17)$. Since families who often 'no show' are less engaged in services (Ingoldsby 2010), this variable represents an objective measure of engagement. The HVR includes home visitor ratings of parent engagement. Home visitors were provided instructions for rating engagement: "Indications of engagement in the activity include: (1) asking questions about materials, (2) asking questions about applications of the topic, (3) seeing the parent apply the concepts discussed, and (4) hearing/seeing the mother talk to other family members about materials concepts discussed." Engagement was rated on the scale: (1) Less than 10\%, (2) $10-24 \%$, (3) $25-50 \%$, (4) $51-75 \%$, (5) $76-90 \%$, and (6) Over $90 \%$. Ratings were aggregated and averaged across home visits, and the mean reflects a high endorsement of engagement $(M=5.48, S D=0.5)$.

\section{Approach to Analysis}

Because the data are nested within program model and home visitor, we computed intraclass correlations (ICCs) to determine whether generalized linear modeling techniques are appropriate. While there is not a clear consensus on the strength of ICCs that require employing multilevel models (MLM), the ICCs for home visitor accounted for more than $5 \%$ of the variance in the engagement and retention outcomes, so they were modeled (Raykov 2011). MLM (Raudenbush and Bryk 2002) refers to a class of statistical techniques developed to analyze and appropriately model clustered designs. This analysis allowed us to explicitly model the variance in engagement and retention accounted for by the home visitor-level effects. Models were fit using R (Bates et al. 2014; R Core Team 2015; Zeileis and Hothorn 2002). We probed significant interaction terms in post hoc simple slope analyses, which investigate the relationship one standard deviation above and below the mean for continuous predictors (Aiken et al. 1991; Dawson and Richter 2006; Preacher et al. 2006). Significant interaction terms indicate that the slopes of the two lines are different from each other; however, it is possible that regression slopes not be statistically different from zero (Preacher et al. 2006).

We used MLM to examine the moderating role of home visiting content on the association between depressive symptoms at enrollment $(0=$ Negative Screening, $1=$ Positive Screening) and the program process outcomes described above. Models included the fixed effects of parental age, race, education, employment, and marital status, the number of adults and children in the home, and child age, as well as the random effect of home visitor and home visiting model. Models included the main effects of depressive symptoms at enrollment, home visiting content, and their interaction. When interaction terms were not significant, we reported the main effects of depression and home visiting content.

Missing data consisted of both invalid assessments and missing values. Assessments given outside the enrollment window were dropped from analysis $(9.8 \%)$. Missing values for variables in the data set were relatively low, ranging from 0.4 to $8.7 \%$. There is some assertion in the literature that small amounts of missing data, 5\% (Schafer 1999) to $10 \%$ (Bennett 2001), are inconsequential. Indeed, a recent study of procedures for handling missing data demonstrated that under the missing at random condition that model estimates were unbiased even in the case of $20 \%$ missing data (Dong and Peng 2013). Because of the small amount of missingness and computational limitations of imputing unbiased categorical estimates in hierarchical data, we analyzed complete cases. 


\section{Results}

\section{Family Retention}

The two-way interaction with the moderator parent-child interaction was significant for predicting retention at $6(B=.08, S E=.03, p=.003)$ and $12(B=.1, S E=.03$, $p=.000$ ) months (see Table 2). Simple slope analyses reveal that a greater amount of time focused on the parent-child relationship is associated with a higher probability of remaining in services at 6 months (Fig. 1) and 12 months (Fig. 2) and that there is a stronger association for parents with higher than lower depressive symptoms at both retention endpoints. The point of intersection (i.e., the point at which the relationship between parent-child interaction content and retention becomes stronger for depressed versus non-depressed families) was $11 \%$ of time across all home visits where content is parent-child interaction focused for retention at 6 months and about $14 \%$ for 12 months. This represents a relatively small percentage of overall home visit time. As the average amount of time spent on parent-child

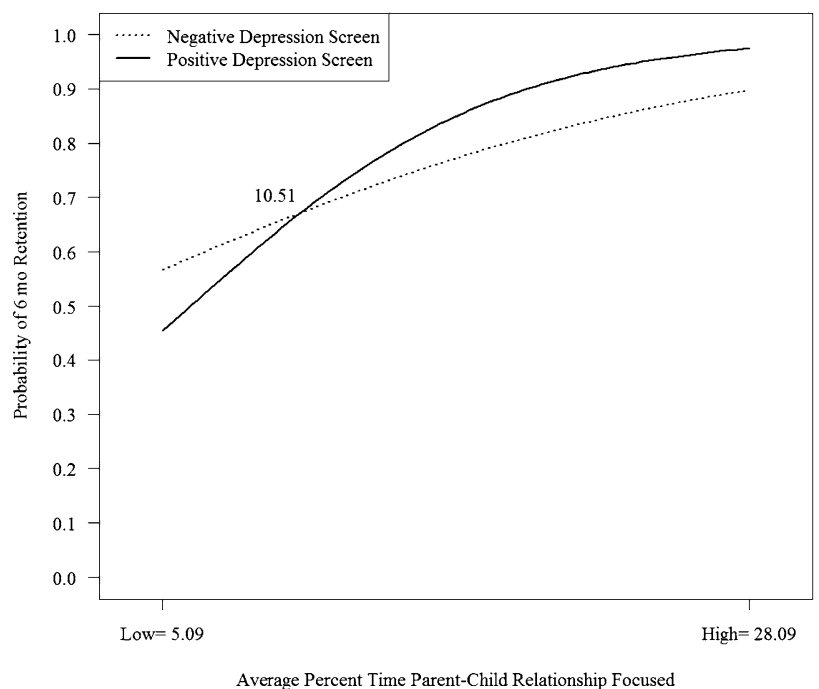

Fig. 1 Interaction of depression screening at enrollment and home visiting time spent focused on supporting the parent-child relationship on retention in services at 6 months

Table 2 Path coefficients of depression screening at enrollment and parent-child relationship focused home visiting content and predicting service retention and engagement

\begin{tabular}{|c|c|c|c|}
\hline \multirow[t]{2}{*}{ Construct } & Retention at 6 months & Retention at 12 months & $\begin{array}{l}\text { Engagement: } \\
\text { home visit com- } \\
\text { pletion }\end{array}$ \\
\hline & B (SE) & B (SE) & B (SE) \\
\hline \multicolumn{4}{|l|}{ Covariates } \\
\hline Parent age at enrollment (years) & $-0.03(0.02)$ & $-0.02(0.02)$ & $-0.001(0.001)$ \\
\hline Child age at enrollment (months) & $-0.01(0.01)$ & $-0.02 *(0.02)$ & $-0.000(0.001)$ \\
\hline Employment & $-0.13(0.14)$ & $-0.04(0.12)$ & $-0.011 \dagger(0.007)$ \\
\hline Parent education & $0.22 * *(0.08)$ & $0.18 * *(0.07)$ & $0.003(0.004)$ \\
\hline Parent race/ethnicity: Black/African American & $-0.02(0.31)$ & $0.04(0.29)$ & $-0.006(0.018)$ \\
\hline Parent race/ethnicity: Native American & $-2.16(1.62)$ & $-0.25(1.43)$ & $0.002(0.1)$ \\
\hline Parent race/ethnicity: Asian & $0.22(0.96)$ & $-0.69(0.63)$ & $-0.009(0.05)$ \\
\hline Parent race/ethnicity: Pacific Islander & $1.28(1.28)$ & $1.72 \dagger(0.96)$ & $0.04(0.05)$ \\
\hline Parent race/ethnicity: Multi-racial & $1.32(1.23)$ & $0.2(0.78)$ & $-0.025(0.05)$ \\
\hline Parent race/ethnicity: Hispanic/Latino & $0.77 *(0.33)$ & $0.73 *(0.29)$ & $0.01(0.017)$ \\
\hline Marital status: married/co-habitation/domestic partnership & $0.37(0.27)$ & $0.31(0.21)$ & $0.03 *(0.013)$ \\
\hline Marital status: separated & $-0.12(0.72)$ & $0.16(0.65)$ & $0.02(0.05)$ \\
\hline Marital status: divorced & $0.45(0.99)$ & $1.39(0.88)$ & $0.03(0.05)$ \\
\hline Marital status: widowed & $-1.46(1.56)$ & $-0.08(1.5)$ & $0.04(0.136)$ \\
\hline Number of minors in the home & $-0.07(0.082)$ & $-0.02(0.07)$ & $-0.006(0.005)$ \\
\hline Number of adults in the home & $-0.17 \dagger(0.09)$ & $-0.19 *(0.08)$ & $-0.007 \dagger(0.005)$ \\
\hline Model $(0=$ HFA, $1=$ PAT $)$ & $0.05(0.47)$ & $0.02(0.42)$ & $0.004(0.05)$ \\
\hline Depression at enrollment $(0=$ No Risk, $1=$ Risk $)$ & $-0.88 *(0.42)$ & $-1.5 * * *(0.42)$ & $-0.05 *(0.03)$ \\
\hline Parent-child relationship focus & $0.08 * * *(0.02)$ & $0.07 * * *(0.01)$ & $0.004 * * *(0.001)$ \\
\hline Depression X parent-child focus & $0.08 * *(0.03)$ & $0.1 * * *(0.03)$ & $0.005 * * *(0.001)$ \\
\hline Constant (SE) & $0.16(0.58)$ & $-1.17 *(0.52)$ & $0.78 * * *(0.04)$ \\
\hline
\end{tabular}

$\dagger p<.10, * p<.05, * * p<.01, * * * \mathrm{p}<.001$ 


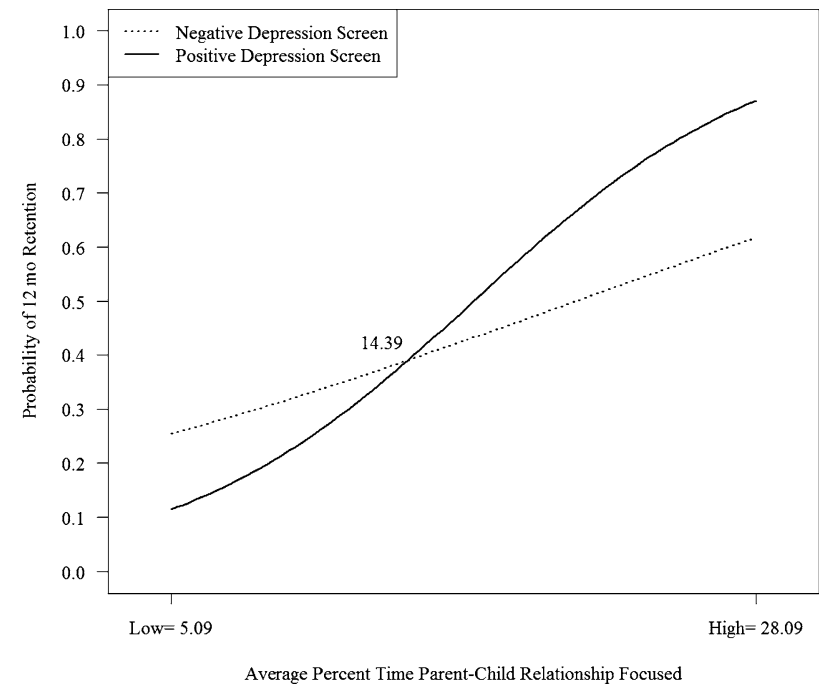

Fig. 2 Interaction of depression screening at enrollment and home visiting time spent focused on supporting the parent-child relationship on retention in services at 12 months

interaction content across all home visits was approximately $17 \%(S D=12 \%)$, the intersection represents onehalf a standard deviation below the average for retention at 6 months and one-quarter a standard deviation below the average for retention at 12 months.

We computed the regions of significance for the interaction, which indicates the value of the moderator (the percentage of time spent focused on parent-child interaction) at which association between depression and retention is significant. For 6 month retention, the lower bound of the region of significance was $9.14(B=-.08, \mathrm{SE}=0.04$, $\mathrm{p}=.05$ ), which is approximately two-thirds of a standard deviation below the mean of time spent focused on parent child interaction. The slope is negative, which indicates that parents who screen positive for depression are significantly more likely to leave services than those who do not when less than average support of the parent-child relationship is provided. The upper bound of the region of significance was $22.01(B=.08, \mathrm{SE}=0.04, \mathrm{p}=.05)$, which is a little over one-third of a standard deviation above the mean of time spent focused on parent child interaction. The slope is positive, which indicates that parents who screen positive for depression are significantly less likely to leave services than those who do not when at more than average support of the parent-child relationship is the focus. For retention at 12 months, the lower bound of the region of significance was $12.17(B=-.08, \mathrm{SE}=0.04, \mathrm{p}=.05)$ and the upper bound was $21.99(B=.09, \mathrm{SE}=0.05, \mathrm{p}=.05)$.

The other areas of program focus, child development and parent/family (case management) did not moderate the association between depression and retention; as such, we interpret their main effects. The main effects of home

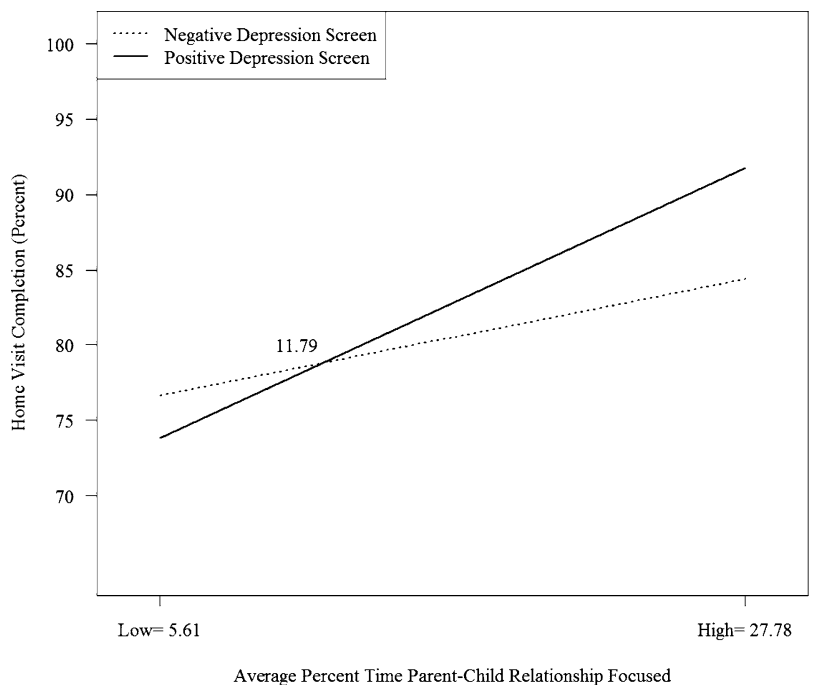

Fig. 3 Interaction of depression screening at enrollment and home visiting time spent focused on supporting the parent-child relationship on home visit completion

visitors staying focused on child development had a positive association with retention at both $6(B=.07, S E=.01$, $p<.001)$ and $12(B=.08, S E=.01, p<.001)$ months. Therefore, the more time home visitors spent focused on child development, the more likely families were to stay in services, regardless of parent depression at enrollment. Home visitors staying focused on parent/family had a negative association with retention at $6(B=-.06, S E=.01, p<.001)$ and $12(B=-.07, S E=.01, p<.001)$ months. This finding suggests the more time home visitors spent focused on case management, the more likely families were to leave services.

\section{Family Engagement: Home Visit Completion}

The two-way interaction with the moderator parent-child interaction was significant for predicting home visit completion $(B=.005, S E=.001, p<.001)$. Simple slope analyses for this interaction (Fig. 3) reveal a positive association between focus on supporting the parent-child relationship and successfully completed home visits, which is stronger for families with higher versus lower depressive symptoms. The point at which the relationship becomes stronger for depressed versus non-depressed families is relatively low, about $12 \%$ of the time across all home visits (i.e., slightly more than one-thirds a standard deviation below the average support for parent-child interaction across all families). The lower bound of the region of significance for home visit completion was $5.73(B=-.04, S E=0.02, p=.05)$, which is approximately one standard deviation below the mean of time spent focused on parent child interaction. The upper bound of the region of significance was $24.74(B=.04$, $S E=0.02, p=.05)$, which is a little over half of a standard 
deviation above the mean of time spent focused on parent child interaction.

As demonstrated with retention, focus on child development or parent/family (case management), did not moderate the association between depression and home visit completion. Focus on child development had a positive association with home visit completion $(B=.002, S E=.001, p<.001)$. The more time home visitors spent focused on child development and parenting to support child development, the more likely families were to complete scheduled home visits. The home visit completion engagement variable was also significantly negatively associated with the time spent parent/ family focused $(B=-.004, S E=.001, p<.001)$. The more time home visitors spent focused on case management, the less likely families were to complete scheduled visits.

\section{Family Engagement: Home Visitor Ratings}

There was no significant moderation of program content on the association between parental depression and home visitor ratings of engagement. The main effect of depression on reported engagement was negative and significant in the models containing parent-child interaction $(B=-.095$, $S E=.045, p=.044)$, child development $(B=-.07$, $S E=.042, p=.049)$, and parent/family case management $(B=-.11, S E=.065, p=.044)$. Therefore, home visitors rated parents entering services with depressive symptoms as less engaged over the course of their services. Main effects of program content suggest that home visitors rate families as more engaged if they spend more time focused on parent/ family case management $(B=.002, S E=.001, p=.03)$. The associations between time spent on parent-child interaction, time spent on child development, and home visitor rating of engagement were non-significant.

\section{Discussion}

Home visiting programs are well suited to support parents with depressive symptoms, such as lack of energy and diminished interest or motivation. Home visiting can reduce these symptoms by improving parent-child interactions and children's development (Chazan-Cohen et al. 2007). However, we know relatively little about what is helpful in retaining and engaging depressed parents in EBHV. The current study examined the moderating role of content provided to families and the association between retention and engagement of depressed mothers in services.

Home visitors can feel pulled in many directions. They must balance the goals of the visit with their desire to meet the family's concrete needs or to spend time nurturing their relationship with family members (Jones Harden et al. 2010). Our findings suggest that all families are more likely to complete visits and to remain in the program when home visitors devote sessions to child development and parent-child interactions. Further, parents with depressive symptoms are enrolled longer and are more engaged when home visitors focus on parent-child interactions.

For all families, there was a negative association between retention and visit completion and having more of a parent/ family (or case management) focus in our services. That association remained even when we controlled for family risks, such as low education or unemployment, that might increase family need for case management. Theoretically, the individualization of services will produce greater parental involvement in home visiting (McCurdy and Daro 2001). Unfortunately, there is some evidence that family's needs may not match the case management services they receive. For example, Tandon et al. (2005) reported over half of mothers participating in HFA experienced domestic violence, substance abuse, and/or a mental health diagnosis. According to HFA service documentation, only one-quarter of those mothers received services related to those risks. There is also data that supports that, in the absence of a home visitor, that families will find ways to meet their referral needs. Findings from one randomized trial of EHS reported that families randomly assigned to EHS were more likely to use the home visitor as a source of instrumental support, while the comparison group reported using neighbors at a higher rate (Mckelvey et al. 2015). Ninety-six percent of parents reported their primary reasons for enrolling in home visiting programs were to improve their parenting and their child's development (Burrell et al. in press). If there is a greater match between their expectations and subsequent experiences, one would theoretically predict greater parent satisfaction (Brown et al. 2008), leading to better retention and engagement (Staudt 2007). Together, these studies suggest a potential mismatch of needs to services in the home visiting field.

While our evaluation did not focus on outcomes, studies suggest that the more time interventionists spend on child development and parent-child interaction content, the more positive the outcomes for parents and children (Pinquart and Teubert 2010; Raikes et al. 2006; Roggman et al. 2016). This holds true even for families at higher levels of sociodemographic risk (Peterson et al. 2013). Our findings further suggest that parents who got more case management in their services were less likely to be retained, decreasing the likelihood of positive outcomes. Therefore, not only are we more likely to lose families, but we may be making our services less effective for families long-term.

In our study, home visitor reports of engagement contrasted with our findings related to retention and home visit completion. When parents screened positive for depression; home visitors negatively rated their engagement. This is not surprising given that depressive symptoms might cause parents to appear less energetic, interested, or enthusiastic. 
Interestingly, home visitors reported better family engagement when more time was spent on case management. Home visitors might feel helpful when they are able to offer concrete, practical support to families (Jones Harden et al. 2010), and perhaps families do show appreciation and thus given higher engagement ratings. Yet overall, our findings suggest this cycle may be counterproductive.

While there are multiple strengths of the study, there are also limitations. A potential limitation of the study is the measure of depression. While the PHQ-2 is a validated instrument, there are differing recommendations for predicting major depression. Further, the manner in which the screening is conducted can have a significant impact on the rate of positive screenings. For example, screening with the PHQ-2 conducted with mothers in pediatric settings demonstrated a significantly higher positive screening rate when the screening was conducted on paper than when done in an interview format (Olson et al. 2005). The PHQ-2 in this study was conducted in an interview format, which may increase the likelihood that parents responded in a more socially desirable way to these sensitive questions. Our analyses used the lower of the recommended thresholds. We did conduct sensitivity analyses using the higher threshold (PHQ-2 scores of 3 or higher), which resulted in similar findings.

Like findings reported in other studies using staff-reported family engagement (Boller et al. 2014; Brophy-Herb et al. 2001), home visitor ratings of engagement were high and skewed to the positive. Measuring engagement as services are being provided, as we did, allows a visit-by-visit account that can be averaged across all services or examined in windows. We provided the home visitors with training and detailed descriptions of what we wanted them to reflect upon as they rated engagement, but there was still limited variability in ratings. Perhaps because the home visit was successfully completed, home visitors were more likely to rate engagement as high.

Home visitors also estimated the percent of time spent on content, which was required to total $100 \%$, during the overall home visit. As a result, the moderators examined are associated. Home visitors must choose the focus of home visits, spending more time in case management, for example, means there was less time to spend on child development and parent-child interaction. Further, the content covered during home visits was not verified by external observation. While we are encouraged that our findings are similar to those conducted using observational coding (Peterson et al. 2007; Roggman et al. 2008), we recommend replications of our findings using observational methods.

There is a natural association between the outcome measures included in the study. The sample retained at 6 months is contained within the sample retained at 12 months. Further, while discharge decisions are likely to differ case-bycase, overall there is evidence that individuals who are less available for home visits may be more likely to leave services
(Holland et al. 2014). Our analyses controlled for family demographics that have been found related to higher attrition from services (Daro et al. 2003; Hicks et al. 2008; Peterson et al. 2013; Roggman et al. 2008). However, the association between demographic risks and involvement in services is not consistent (Ammerman et al. 2006) or even linear (Korfmacher et al. 2008). It is impossible to disentangle the direction of influence between family characteristics and services in this study. These analyses were of natural variations in EBHV in one state and do not imply causation. We recommend replication of the findings in future studies. A controlled trial of additional supports for parent-child interaction could also be conducted.

The findings from the evaluation are relevant and useful to the field. They suggest the need to remain faithful to the primary purpose of services, supporting parenting and the parent-child relationship, and ultimately child outcomes (Raikes et al. 2014). In the words of the author Stephen Covey, "The main thing is to keep the main thing the main thing." This is particularly important when thinking about the role of home visitors. A recent study included interviews with home visitors specific to their roles in supporting parent-child interactions (Jones Harden et al. 2010). Home visitors primarily reported feeling the need to focus on meeting families' basic needs with case management work before supporting parent-child interaction during home visits, but they also reported worries that focusing on parent-child interaction could be counterproductive for parents who were emotionally vulnerable and struggled with the "distinction between facilitating and directing parent-child interaction" (p. 375). It is vital to support home visitors in their efforts to balance the complex needs of families while also individualizing services that remain focused on the key elements of services.

Acknowledgements Funding for this study was made possible by the Health Resources and Services Administration (HRSA) of the U.S. Department of Health and Human Services (HHS) under grant number D89MC23141 of the Affordable Care Act - Maternal, Infant, and Early Childhood Home Visiting Program awarded to the Arkansas Department of Health. The information or content and conclusions expressed in this material or by speakers and moderators are those of the author(s) and should not be construed as the official position or policy of, nor should any endorsements be inferred by HRSA, HHS, or the U.S. Government.

Open Access This article is distributed under the terms of the Creative Commons Attribution 4.0 International License (http://creativeco mmons.org/licenses/by/4.0/), which permits unrestricted use, distribution, and reproduction in any medium, provided you give appropriate credit to the original author(s) and the source, provide a link to the Creative Commons license, and indicate if changes were made.

\section{References}

Aiken, L. S., West, S. G., \& Reno, R. R. (1991). Multiple regression: Testing and interpreting interactions. Thousand Oaks, CA: SAGE. 
Ammerman, R. T., Altaye, M., Putnam, F. W., Teeters, A. R., Zou, Y., \& Van Ginkel, J. B. (2015). Depression improvement and parenting in low-income mothers in home visiting. Archives of Women's Mental Health, 18(3), 555-563. https://doi.org/10.1007/ s00737-014-0479-7.

Ammerman, R. T., Putnam, F. W., Altaye, M., Chen, L., Holleb, L. J., Stevens, J., ... Van Ginkel, J. B. (2009). Changes in depressive symptoms in first time mothers in home visitation. Child Abuse and Neglect, 33(3), 127-138. https://doi.org/10.1016/j. chiabu.2008.09.005.

Ammerman, R. T., Steens, J., Putnam, F. W., Altaye, M., Hulsmann, J. E., Lehmkuhl, H. D., ... Van Ginkel, J. B. (2006). Predictors of early engagement in home visitation. Journal of Family Violence, 21(2), 105-115. https://doi.org/10.1007/s10896-005-9009-8.

Arroll, B., Goodyear-Smith, F., Crengle, S., Gunn, J., Kerse, N., Fishman, T., ... Hatcher, S. (2010). Validation of PHQ-2 and PHQ-9 to screen for major depression in the primary care population. Annals of Family Medicine, 8(4), 348-353. https://doi. org/10.1370/afm.1139.

Azzi-Lessing, L. (2011). Home visitation programs: Critical issues and future directions. Early Childhood Research Quarterly, 26(4), 387-398. https://doi.org/10.1016/j.ecresq.2011.03.005.

Azzi-Lessing, L. (2013). Serving highly vulnerable families in homevisitation programs. Infant Mental Health Journal, 34(5), 376390. https://doi.org/10.1002/imhj.21399.

Bates, D., Mächler, M., Bolker, B., \& Walker, S. (2014). Fitting linear mixed-effects models using lme4. Journal of Statistical Software. https://doi.org/10.18637/jss.v067.i01.

Bennett, D. A. (2001). How can I deal with missing data in my study? Australian and New Zealand Journal of Public Health, 25(5), 464-469. https://doi.org/10.1111/j.1467-842X.2001.tb00294.x.

Boller, K., Daro, D., Del Grosso, P., Cole, R., Paulsell, D., Hart, B., ... Hargreaves, M. (2014). Making replication work: Building infrastructure to implement, scale-up, and sustain evidence-based early childhood home visiting programs with fidelity. Washington, DC: Children's Bureau, Administration for Children and Families, US Department of Health and Human Services.

Booth, A., Munsell, E. P., \& Doyle, O. (2014). Maternal engagement in a home visiting intervention: What lies beneath psychological resources? Journal of Community Psychology, 42(1), 29-46. https ://doi.org/10.1002/jcop.21592.

Brand, T., \& Jungmann, T. (2014). Participant characteristics and process variables predict attrition from a home-based early intervention program. Early Childhood Research Quarterly, 29(2), 155-167. https://doi.org/10.1016/j.ecresq.2013.12.001.

Brophy-Herb, H., Schiffman, R., McKelvey, L. M., CunninghamDeluca, M., \& Hawver, M. (2001). Innovations in practice quality improvement: Lessons learned from an infant mental health-based early head start program. Infants \& Young Children, 14(2), 77-85.

Brown, S., Venkatesh, V., Kuruzovich, J., \& Massey, A. P. (2008). Expectation confirmation: An examination of three competing models. Organizational Behavior and Human Decision Processes, 105(1), 52-66. https://doi.org/10.1016/j.obhdp.2006.09.008.

Burrell, L., Crowne, S., Ojo, K., Snead, R., O’Neill, K., Cluxton-Keller, F., \& Duggan, A. (in press). Characteristics of mothers and visitors and their alignment on goals for home visiting as factors for program engagement. Maternal and Child Health Journal.

Chazan-Cohen, R., Ayoub, C., Pan, B. A., Roggman, L., Raikes, H. H., McKelvey, L. M., ... Hart, A. (2007). It takes time: Impacts of early head start that lead to reductions in maternal depression two years later. Infant Mental Health Journal, 28(2), 151-170. https:// doi.org/10.1002/imhj.20127.

Conners-Burrow, N. A., Bokony, P., Whiteside-Mansell, L., Jarrett, D., Kraleti, S., McKelvey, L. M., \& Kyzer, A. (2014). Low-level depressive symptoms reduce maternal support for child cognitive development. Journal of Pediatric Health Care, 28(5), 404-412. https://doi.org/10.1016/j.pedhc.2013.12.005.

Conners-Burrow, N. A., McKelvey, L. M., Perry, D., WhitesideMansell, L., Kraleti, S., Mesman, G. R., ... Kyzer, A. (2016). Low-level symptoms of depression in mothers of young children are associated with behavior problems in middle childhood. Maternal and Child Health Journal, 20(3), 516-524. https://doi. org/10.1007/s10995-015-1849-0.

Conners-Burrow, N. A., Swindle, T., McKelvey, L. M., \& Bokony, P. (2015). A little bit of the blues: Low-level symptoms of maternal depression and classroom behavior problems in preschool children. Early Education and Development, 26(2), 230-244. https:// doi.org/10.1080/10409289.2015.979725.

Damashek, A., Doughty, D., Ware, L., \& Silovsky, J. (2011). Predictors of client engagement and attrition in home-based child maltreatment prevention services. Child Maltreatment, 16(1), 9-20. https ://doi.org/10.1177/1077559510388507.

Daro, D., McCurdy, K., Falconnier, L., \& Stojanovic, D. (2003). Sustaining new parents in home visitation services: Key participant and program factors. Child Abuse and Neglect, 27(10), 11011125. https://doi.org/10.1016/j.chiabu.2003.09.007.

Dawson, J. J. F., \& Richter, A. A. W. (2006). Probing three-way interactions in moderated multiple regression: Development and application of a slope difference test. The Journal of Applied Psychology, 91(4), 917-926. https://doi.org/10.1037/0021-9010.91.4.917.

Dong, Y., \& Peng, C.-Y. J. (2013). Principled missing data methods for researchers. SpringerPlus, 2(1), 222. https://doi. org/10.1186/2193-1801-2-222.

Foulon, S., Greacen, T., Pasquet, B., Dugravier, R., Saïas, T., Guedeney, N., ... Tubach, F. (2015). Predictors of study attrition in a randomized controlled trial evaluating a perinatal home-visiting program with mothers with psychosocial vulnerabilities. PLOS ONE, 10(11), e0142495. https://doi.org/10.1371/journal.pone.0142495.

Girvin, H., DePanfilis, D., \& Daining, C. (2007). Predicting program completion among families enrolled in a child neglect preventive intervention. Research on Social Work Practice, 17(6), 674-685. https://doi.org/10.1177/1049731507300285.

Hicks, D., Larson, C., Nelson, C., Olds, D. L., \& Johnston, E. (2008). The influence of collaboration on program outcomes: The Colorado Nurse-Family Partnership. Evaluation Review, 32(5), 453477. https://doi.org/10.1177/0193841X08315131.

Holland, M. L., Christensen, J. J., Shone, L. P., Kearney, M. H., \& Kitzman, H. J. (2014). Women's reasons for attrition from a nurse home visiting program. Journal of Obstetric, Gynecologic, and Neonatal Nursing: JOGNN, 43(1), 61-70. https://doi. org/10.1111/1552-6909.12263.

Ingoldsby, E. M. (2010). Review of interventions to improve family engagement and retention in parent and child mental health programs. Journal of Child and Family Studies, 19(5), 629-645. https ://doi.org/10.1007/s10826-009-9350-2.

Jones Harden, B., Denmark, N., \& Saul, D. (2010). Understanding the needs of staff in Head Start programs: The characteristics, perceptions, and experiences of home visitors. Children and Youth Services Review, 32(3), 371-379. https://doi.org/10.1016/j.child youth.2009.10.008.

Korfmacher, J., Green, B., Staerkel, F., Peterson, C. A., Cook, G., Roggman, L., ... Schiffman, R. (2008). Parent involvement in early childhood home visiting. Child and Youth Care Forum, 37(4), 171-196. https://doi.org/10.1007/s10566-008-9057-3.

Kroenke, K., Spitzer, R. L., \& Williams, J. B. W. (2003). The patient health questionnaire-2: Validity of a two-item depression screener. Medical Care, 41(11), 1284-1292. https://doi.org/10.1097/01. MLR.0000093487.78664.3C.

Lovejoy, M. C. C., Graczyk, P. A., O'Hare, E., \& Neuman, G. (2000). Maternal depression and parenting behavior. Clinical 
Psychology Review, 20(5), 561-592. https://doi.org/10.1016/ S0272-7358(98)00100-7.

McCurdy, K., \& Daro, D. (2001). Parent involvement in family support programs: An integrated theory. Family Relations, 50(2), 113-121. https://doi.org/10.1111/j.1741-3729.2001.00113.x.

Mckelvey, L. M., Schiffman, R. F., Brophy-Herb, H. E., Bocknek, E. L., Fitzgerald, H. E., Reischl, T. M., ... Deluca, M. C. (2015). Examining long-term effects of an infant mental health home-based early head start program on family strengths and resilience. Infant Mental Health Journal, 36(4), 353-365. https://doi.org/10.1002/ imhj.21518.

MDRC. (2017). A profile of women when they enrolled in MIHOPE. Retrieved May 8, 2017, from http://www.mdrc.org/profile-women -when-they-enrolled-mihope.

Navaie-Waliser, M., Martin, S. L., Campbell, M. K., Tessaro, I., Kotelchuck, M., \& Cross, A. W. (2000). Factors predicting completion of a home visitation program by high-risk pregnant women: The North Carolina Maternal Outreach Worker Program. American Journal of Public Health, 90(1), 121-124. https://doi.org/10.2105/ AJPH.90.1.121.

O’Brien, R. A., Moritz, P., Luckey, D. W., McClatchey, M. W., Ingoldsby, E. M., Olds, D. L., ... Olds, D. L. (2012). Mixed methods analysis of participant attrition in the nurse-family partnership. Prevention Science, 13(3), 219-228. https://doi.org/10.1007/ s11121-012-0287-0.

Olson, A. L., Dietrich, A. J., Prazar, G., Hurley, J., Tuddenham, A., Hedberg, V., \& Naspinsky, D. A. (2005). Two approaches to maternal depression screening during well child visits. Journal of Developmental \& Behavioral Pediatrics, 26(3), 169-176.

Peterson, C. A., Luze, G. J., Eshbaugh, E. M., Jeon, H.-J., \& Kantz, K. R. (2007). Enhancing parent-child interactions through home visiting: Promising practice or unfulfilled promise? Journal of Early Intervention, 29(2), 119-140. https://doi.org/10.1177/10538 1510702900205

Peterson, C. A., Roggman, L. A., Green, B., Chazan-Cohen, R., Korfmacher, J., McKelvey, L. M., ... Atwater, J. B. (2013). Home visiting processes: Relations with family characteristics and outcomes. Zero to Three, 33(3), 39-44. Retrieved from http://eric. ed.gov/?id=EJ1003939.

Pignone, M. P., Gaynes, B. N., Rushton, J. L., Burchell, C. M., Orleans, C. T., Mulrow, C. D., \& Lohr, K. N. (2002). Screening for depression in adults: A summary of the evidence for the U.S. preventive services task force. Annals of Internal Medicine, 136(10), 765. https://doi.org/10.7326/0003-4819-136-10-200205210-00013.

Pinquart, M., \& Teubert, D. (2010). Effects of parenting education with expectant and new parents: A meta-analysis. Journal of Family Psychology, 24(3), 316-327. https://doi.org/10.1037/a0019691.

Preacher, K. J. K., Curran, P. J. P., \& Bauer, D. J. (2006). Computational tools for probing interactions in multiple linear regression, multilevel modeling, and latent curve analysis. Journal of Educational and Behavioral Statistics, 31(4), 437-448. https://doi. org/10.3102/10769986031004437.

R Core Team. (2015). R: The R Project for Statistical Computing. Vienna: R Core Team. Retrieved from https://www.r-project.org/.

Raikes, H. H., Green, B. L., Atwater, J., Kisker, E., Constantine, J., \& Chazan-Cohen, R. (2006). Involvement in early head start home visiting services: Demographic predictors and relations to child and parent outcomes. Early Childhood Research Quarterly, 21(1), 2-24. https://doi.org/10.1016/j.ecresq.2006.01.006.

Raikes, H. H., Roggman, L. A., Peterson, C. A., Brooks-Gunn, J., Chazan-Cohen, R., Zhang, X., \& Schiffman, R. F. (2014). Theories of change and outcomes in home-based Early Head Start programs. Early Childhood Research Quarterly, 29(4), 574-585. https://doi.org/10.1016/j.ecresq.2014.05.003.
Raudenbush, S. W., \& Bryk, A. S. (2002). Hierarchical linear models: Applications and data analysis methods. Thousand Oaks, CA: SAGE.

Raykov, T. (2011). Intraclass correlation coefficients in hierarchical designs: Evaluation using latent variable modeling. Structural Equation Modeling: A Multidisciplinary Journal, 18(1), 73-90. https://doi.org/10.1080/10705511.2011.534319.

Roggman, L. A., Cook, G. A., Innocenti, M. S., Jump Norman, V., Boyce, L. K., Christiansen, K., \& Peterson, C. A. (2016). Home visit quality variations in two Early Head Start Programs in relation to parenting and child vocabulary outcomes. Infant Mental Health Journal, 37(3), 193-207. https://doi.org/10.1002/ imhj. 21565.

Roggman, L. A., Cook, G. A., Peterson, C. A., \& Raikes, H. H. (2008). Who drops out of early head start home visiting programs? Early Education and Development, 19(4), 574-599. https://doi. org/10.1080/10409280701681870.

Sanders, M. R., Markie-Dadds, C., Tully, L. A., \& Bor, W. (2000). The triple P-positive parenting program: A comparison of enhanced, standard, and self-directed behavioral family intervention for parents of children with early onset. Journal of Consulting and Clinical Psychology, 68(4), 624-640. Retrieved from http://doi. apa.org/journals/ccp/68/4/624.html.

Schafer, J. L. (1999). Multiple imputation: A primer. Statistical Methods in Medical Research, 8(1), 3-15. https://doi. org/10.1177/096228029900800102.

Social Solutions. (2016). Case management software I Efforts to Outcomes Software I SSI. Retrieved February 11, 2016, from http:// www.socialsolutions.com/case-management-software/.

Staudt, M. (2007). Treatment engagement with caregivers of at-risk children: Gaps in research and conceptualization. Journal of Child and Family Studies, 16(2), 183-196. https://doi.org/10.1007/ s10826-006-9077-2.

Sweet, M. A., \& Appelbaum, M. I. (2004). Is home visiting an effective strategy? A meta-analytic review of home visiting programs for families with young children. Child Development, 75(5), 14351456. https://doi.org/10.1111/j.1467-8624.2004.00750.x.

Tandon, S. D., Parillo, K. M., Jenkins, C., \& Duggan, A. K. (2005). Formative evaluation of home visitors' role in addressing poor mental health, domestic violence, and substance abuse among low-income pregnant and parenting women. Maternal and Child Health Journal, 9(3), 273-283.

Vogel, C. A., Boller, K., Xue, Y., Blair, R., Aikens, N., Burwick, A., ... Stein, J. (2011). Learning as we Go: A first snapshot of early head start programs, staff, families, and children. DC. Retrieved from http://www.acf.hhs.gov/sites/default/files/opre/as_we_go_tech. pdf.

Whiteside-Mansell, L., Bradley, R., Conners, N., \& Bokony, P. (2007). The family map: Structured family interview to identify risks and strengths in head start families. NHSA Dialog, 10(3-4), 189-209. https://doi.org/10.1080/15240750701742239.

Whiteside-Mansell, L., Johnson, D., Bokony, P., Mckelvey, L. M., Conners-Burrow, N., Swindle, T., \& Conners-, N. (2013). Supporting Family Engagement with Parents of Infants and Toddlers. NHSA Dialog, 16(1), 20-44. Retrieved from https://journals.uncc.edu/ dialog/article/view/42.

Zeileis, A., \& Hothorn, T. (2002). Diagnostic checking in regression relationships. $R$ News, 2(3), 7-10. Retrieved from http://cran.rproject.org/doc/Rnews. 